\title{
Changes in terrestrial surface dry and wet conditions on the Loess Plateau (China) during the last half century
}

\author{
YuBi YAO ${ }^{1,2,3,4 *}$, RunYuan WANG ${ }^{1}$, JinHu YANG ${ }^{4}$, Ping $\mathrm{YUE}^{1}$, DengRong $\mathrm{LU}^{5}$, GuoJu XIAO ${ }^{6}$, \\ Yang WANG ${ }^{4}$, LinChun LIU ${ }^{4}$ \\ ${ }^{1}$ China Meteorological Administration Key Laboratory of Arid Climate Change and Reducing Disaster, Lanzhou 730020, China; \\ ${ }^{2}$ Gansu Province Key Laboratory of Arid Climate Change and Reducing Disaster, Lanzhou 730020, China; \\ ${ }^{3}$ Lanzhou Institute of Arid Meteorology, China Meteorological Administration, Lanzhou 730020, China; \\ ${ }^{4}$ Meteorological Bureau of Dingxi City, Dingxi 743000, China; \\ ${ }^{5}$ Gansu Meteorological Information Center, Lanzhou 730020, China; \\ ${ }^{6}$ New Technology Application Research and Development Centre of Ningxia University, Yinchuan 750021, China
}

\begin{abstract}
This paper, using a revised Penman-Monteith model, computed the terrestrial surface humidity index of the Loess Plateau (China) based on climatic factors of monthly mean temperature, maximum temperature, minimum temperature, relative humidity, precipitation, wind speed and sunshine duration observed on the plateau from 1961 to 2008. The temporal-spatial distribution, anomaly distribution and sub-regional temporal variations of the terrestrial surface dry and wet conditions were analyzed as well. The results showed a decreasing trend in the annual average surface humidity from the southeast to the northwest in the research area. Over the period of 1961-2008, an aridification tendency appeared sharply in the central interior region of the Loess Plateau, and less sharply in the middle part of the region. The border region showed the weakest tendency of aridification. It is clear that aridification diffused in all directions from the interior region. The spatial anomaly distribution of the terrestrial surface dry and wet conditions on the Loess Plateau can be divided into three key areas: the southern, western and eastern regions. The terrestrial annual humidity index displayed a significantly descending trend and showed remarkable abrupt changes from wet to dry in the years 1967, 1977 and 1979. In the above mentioned three key areas for dry and wet conditions, the terrestrial annual humidity index exhibited a fluctuation period of 3-4 years, while in the southern region, a fluctuation period of 7-8 years existed at the same time.
\end{abstract}

Keywords: dry and wet conditions; spatial distribution; temporal variation; Penman-Monteith model; Loess Plateau

Citation: YuBi YAO, RunYuan WANG, JinHu YANG, Ping YUE, DengRong LU, GuoJu XIAO, Yang WANG, LinChun LIU. 2013. Changes in terrestrial surface dry and wet conditions on the Loess Plateau (China) during the last half century. Journal of Arid Land, 5(1): 15-24.

The newly issued IPCC SREX Summary for Policymakers reported that climate change could cause changes in frequency, intensity, spatial dimension, duration and timing of climatic extremes and climate events, and could result in the occurrence of unprecedented climatic extremes and climate events (IPCC, 2012). Research on the influences of climate warming has become a hot scientific issue at home and abroad (Ci et al., 2002; IPCC, 2007; Zhang et al., 2008). On the other hand, more and more scientists have been paying close attention to changes in water regimes caused by climate change, making the issue of regional dry and wet conditions another hot topic (Chattopadhyay and Hulme, 1997; Thomas, 2000; Chen et al., 2006; Xie and Wang, 2007).

The southern and northern areas of Xinjiang display relatively higher humidity in winter and lower humidity in other seasons. The surface humidity index in Tibet has displayed an increasing trend during the past 35 years (Du et al., 2009; Li et al., 2012). However, the eastern region of Northwest China has been experiencing a warming and drying climate with a

\footnotetext{
*Corresponding author: YuBi YAO (E-mail: yaoyubi@163.com) Received 2012-05-02; revised 2012-06-28; accepted 2012-07-10

(c) Xinjiang Institute of Ecology and Geography, Chinese Academy of Sciences, Science Press and Springer-Verlag Berlin Heidelberg 2013
} 
semi-arid boundary in the southern part of Shanxi extending southward to $32.6^{\circ} \mathrm{N}$ ( $\mathrm{Ma}$ and $\mathrm{Fu}, 2005$ ). The temperature of the eastern region of Northwest China displayed a linear increasing trend while the precipitation and surface humidity index displayed linear declining trends. The overall trend was toward warming, less precipitation and aridification. Especially after the 1990 s, there were significantly more extreme droughts in the eastern region of Northwest China with a more than two-fold increase ( $\mathrm{Ma}$ and $\mathrm{Fu}, 2001 ; \mathrm{Ma}, 2005$ ). Research found that in China the area of increasing wetness was larger than the area of increasing dryness although the course of aridification developed faster than that of humidification (Shen et al., 2009). So far, however, no specific researches on dry and wet changes for the Loess Plateau have been carried out.

The Loess Plateau lies in the marginal zone of the East Asian and South Asian summer monsoon and is the zone of intersection between the east-west moisture gradient and the south-north heat gradient. Being relatively sensitive to the advance and retreat and intensity of the monsoon ( $\mathrm{Lu}, 2009$ ), it is the zone transitioning not only from the humid monsoon climate to the inland arid climate, but also from the deciduous broadleaved forest of the warm temperate zone to the sensitive and ecologically fragile steppe and desert-steppe regions (Zhang et al., 2011). The Loess Plateau is the key area for conservation of water and soil along the middle and upper reaches of the Yellow River, and the shortage of water resources is always the crucial factor constraining the recovery and reconstruction of its vegetation. In the semiarid and arid areas of the Loess Plateau the main source of root zone water consumption is evapotranspiration. Studying the dynamics of terrestrial surface dry and wet conditions on the Loess Plateau is a key step for research on water dynamics in the soil-vegetation-atmospheric continuum, as well as the key step to determine the water requirements of the regional ecosystem (Zhou, 2000; Wang et al., 2008a). Over the past 40 years, the Loess Plateau has experienced increasing temperature, declining precipitation and climatic warming and drying trends (Yao et al., 2005). The precipitation in this region shows a decreasing trend (Liu et al., 2008; Guo et al., 2011). Currently, there is insufficient discussion on the distributional characteristics of terrestrial surface dry and wet conditions on the Loess Plateau. By analyzing the characteristics of changing trends of the terrestrial surface humidity index on the Loess Plateau and anomaly changes of temporal and spatial distributions, this paper identified the differences between the current and past situations of climatic ecology and sheds light on the relationships between soil water consumption and climatic change.

\section{Study area and methods}

\subsection{Study area}

The Loess Plateau lies in the middle and upper reaches of the Yellow River and in the upper reaches of the Haihe River. It starts from the Taihang Mountains in the east, reaches the Riyue Mountain in the west, borders on the Qinling Mountains in the south and adjoins the Erdos Plateau in the north. Its geographical coordinates fall between $33^{\circ} 47^{\prime}-40^{\circ} 44^{\prime} \mathrm{N}$ and $100^{\circ} 56^{\prime}-114^{\circ} 12^{\prime} \mathrm{E}$. It has an area of $51.7 \times 10^{4} \mathrm{~km}^{2}$, covering the western part of Hebei, the most of Shanxi, the middle and northern parts of Shaanxi, the middle and eastern parts of Gansu, the southern part of Ningxia, and the eastern part of Qinghai, and supports a population of about $100 \times 10^{6}$ (Wang et al., 2004).

The study area has a distinguishing climate characterized by a large diurnal temperature range, dry and cold winters, hot and humid summers, rapid temper. ature reduction in autumn and rapid temperature rise in spring. The annual precipitation falls between $150-900 \mathrm{~mm}$ and the annual average precipitation for about $2 / 3$ of the plateau is below $450 \mathrm{~mm}$ (Zhao et al., 2003).

The Loess Plateau has an annual mean temperature of $0-12^{\circ} \mathrm{C}$, with the mean temperature for the coldest month (January) being $-1--7^{\circ} \mathrm{C}$ and the mean temperature for the hottest month (July) being $18-28^{\circ} \mathrm{C}$. The accumulated temperature of $\geq 0^{\circ} \mathrm{C}$ is $2,500-5,600^{\circ} \mathrm{C}$ and the accumulated temperature of $\geq 10^{\circ} \mathrm{C}$ is $3,000-4,000^{\circ} \mathrm{C}$. It has abundant light energy resources, with 2,200-2,800 $\mathrm{h}$ for annual hours of sunshine and $5,000 \times 10^{6}-6,300 \times 10^{6} \mathrm{~J} / \mathrm{m}^{2}$ for annual total solar heat gain. The light energy resources present an increasing trend along the route from the southeast to the northwest (Liu and Wang, 2002). 


\subsection{Data}

The climatic data (from 1961 to 2008) of monthly mean temperature over the years, maximum temperature, minimum temperature, relative humidity, precipitation, wind speed and sunshine duration were from 50 stations in seven provinces of the Loess Plateau.

The selected stations are national principal ones, 11 of which are located in Gansu, 3 in Qinghai, 12 in Shaanxi, 14 in Shanxi, 6 in Ningxia, 3 in Henan and 1 in Hebei. The methods of observation, and instruments and equipment adopted by the stations comply with national unified standards. The data have good representativeness and continuity, and is in continuous sequence before and after changes of individual station sites. No obvious change occurred.

\subsection{Humidity index}

The humidity index refers to an ideal physical quantity which can represent the terrestrial surface dry and wet conditions (Deng, 1979). There are many methods to calculate the index (Jesen et al., 1990) and the Penman-Monteith (P-M) model (Allen et al., 1998) recommended and revised by the Food and Agriculture Organization of the United Nations (FAO) in 1998 was adopted in this paper. The P-M model has been widely used throughout the world (Walter et al., 2000) with its computing formula as follows:

$$
k=\frac{R}{E T_{0}} .
$$

Where, $k$ refers to surface humid index, $R$ precipitation $(\mathrm{mm}), E T_{0}$ maximum potential evapotranspiration $(\mathrm{mm})$.

$$
\begin{gathered}
E T_{0}=\frac{0.408 \Delta\left(R_{n}-G_{i}\right)+\gamma \frac{900}{T+273} U_{2}\left(e_{s}-e_{a}\right)}{\Delta+\gamma\left(1+0.34 U_{2}\right)}, \\
R_{n}=0.77 \times\left(0.248+0.752 \frac{n}{N}\right) R_{s o}- \\
\sigma\left(\frac{\left.T_{\max , k}^{4}+T_{\min , k}^{4}\right)\left(0.56-0.08 \sqrt{e_{a}}\right)\left(0.1+0.9 \frac{n}{N}\right),}{2}=0.14\left(T_{i}-T_{i-1}\right),\right. \\
U_{2}=U_{10} \frac{4.87}{\ln (67.8 \times 10-5.42)}=0.75 U_{10}, \\
\Delta=\frac{4098\left[0.6108 \exp \left(\frac{17.27 T}{T+237.3}\right)\right]}{(T+237.3)^{2}} .
\end{gathered}
$$

Where, $R_{n}$ refers to net surface radiation $\left(\mathrm{MJ} /\left(\mathrm{m}^{2} \cdot \mathrm{d}\right)\right)$ (Zuo et al., 1993), $G_{i}$ soil heat flux $\left(\mathrm{MJ} /\left(\mathrm{m}^{2} \cdot \mathrm{d}\right)\right), \gamma$ a psychrometer constant $\left(\mathrm{kPa} /{ }^{\circ} \mathrm{C}\right), \Delta$ the slope of the saturation vapour pressure curve $\left(\mathrm{kPa} /{ }^{\circ} \mathrm{C}\right), T$ mean temperature $\left({ }^{\circ} \mathrm{C}\right), U_{2}$ and $U_{10}(\mathrm{~m} / \mathrm{s})$ the mean wind speed at the heights of $2 \mathrm{~m}$ and $10 \mathrm{~m}$ respectively, $e_{s}$ saturation vapour pressure $(\mathrm{kPa}), e_{a}$ actual vapor pressure $(\mathrm{kPa}), n$ actual hours of sunshine (h), $N$ available sunshine hours $(\mathrm{h}), R_{s o}$ sunshine radiation $\left(\mathrm{MJ} /\left(\mathrm{m}^{2} \cdot \mathrm{d}\right)\right), \quad \sigma$ the Stefan-Boltzmann constant $\left(4.903 \times 10^{-9} \mathrm{MJ} /\left(\mathrm{K}^{4} \mathrm{~m}^{2} \cdot \mathrm{d}\right)\right), T_{\max , k}$ and $T_{\min , k}$ the maximum and minimum temperatures of the thermodynamic temperature scale $(\mathrm{K})$ respectively, $T_{i}$ and $T_{i-1}$ the mean temperatures of the current month and the previous month respectively.

\subsection{Method of analysis}

The change in the trend of the climatic factors is expressed with the climatic tendency rate (Wei, 2007). A climatic variable of the sample $n$ is expressed with $X_{i}$ and the time corresponding to $X_{i}$ is expressed with $t_{i}$ to establish the simple linear regression equation between $X_{i}$ and $t: X_{i}=a+b t_{i}(i=1,2, \ldots, n)$. Where, $a$ is for the regression constant; $b$ is for the regression coefficient; $a$ and $b$ can be estimated with the least-square method; and $10 \times b$ can serve as the climatic tendency rate for climatic factors.

Wavelet analysis can, in addition to reflecting the overall characteristics of signals in time-frequency domains and provisioning localized information, provide the time scale for signal change and determine the time location of signal changes, as well as diagnose abrupt change points. Wavelet analysis has been widely applied in many fields. Many kinds of wavelet basis (mother wavelets) and boundary-available Morlet wavelet energy spectrum analysis were adopted in this paper (Wei, 2007).

The Mann-Kendall (M-K) trend test (Mann, 1945; Kendall, 1975) can detect trends in a time series without requiring normality or linearity (Wang et al., 2008b) and is therefore highly recommended for general use by the World Meteorological Organization (Mitchell et al., 1966). It is widely used in the detection of trends in hydrological series and meteorological series (Zhang et al., 2006). It defines statistics for variance tests under circumstances in which there 
is no change in an originally hypothesized climatic sequence. If the ordinal statistics curve surpasses the reliability critical line, it means that there is then a remarkable change in trend. The point of interaction between the ordinal statistics curve and converse statistics curve will be the point where the abrupt change begins if it falls between reliability critical lines.

The experiential orthogonal function (EOF) (Wu and $\mathrm{Wu}, 2005)$ and the rotated experiential orthogonal function (REOF) analysis (Ding and Shi, 1992; Wang and Yang, 2007) were adopted for the characteristics for anomaly distribution.

\section{Results and discussion}

\subsection{Temporal and spatial distribution of dry and wet conditions}

Figure 1 shows the spatial distribution of the annual average terrestrial surface humidity index on the Loess Plateau during 1961-2008, from which emerges a decreasing trend along the route from southeast to northwest. $K>1$ represents the humid region, $0.67<K \leq 1$ the semi-humid region, $0.25<K<0.67$ the semi-arid region and $K \leq 0.25$ the arid region (Wu et al., 2005). From Figure 1, it can be seen that the northwestern part of the Loess Plateau is mainly semi-arid region and its southeastern part is mainly semi-humid region. The characteristics of the spatial distribution of the annual average humid index in the study area is directly proportional in terms of phase change to the spatial distribution of the annual precipitation and annual mean temperature. The precipitation and mean temperature are the major climatic factors influencing the humid index.

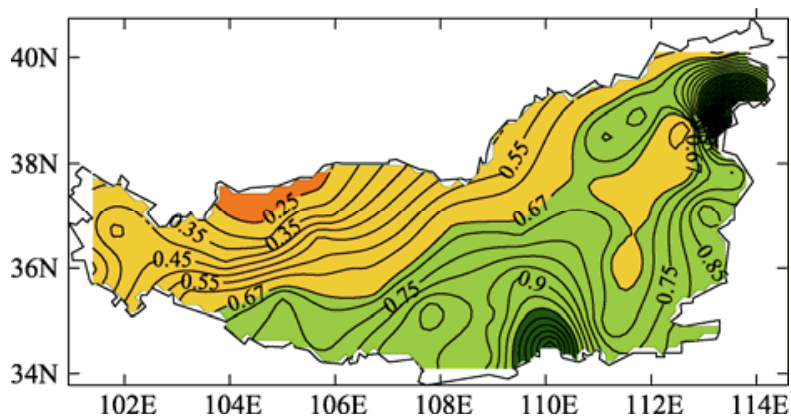

Fig. 1 Spatial distribution of the average humidity index in the Loess Plateau from 1961 to 2008
The trend change of the terrestrial surface dry and wet conditions from 1961 to 2008 showed that the annual humidity index of the Loess Plateau (some regions in the western part are excluded) manifested a decreasing trend. Significance tests for the majority of stations show linear curve fitting tendency rates for most regions to fall between $-0.04--0.02 / 10 \mathrm{a}$ (Fig. 2 ), whereas the rates for the interior regions of Loess Plateau are less than $-0.04 / 10$ a and the rates for the border area are more than $-0.02 / 10$ a. From this, it can be seen that aridification tendency on the Loess Plateau appeared sharply in the interior region and less sharply in the middle part of the region with the border region showing the weakest tendency to aridification (some regions in the western part showed a tendency of humidification). It is clear that aridification was diffused from the interior region to all directions around, and such a trend is consistent with the warming-drying climatic characteristics of this area (Yao et al., 2005).

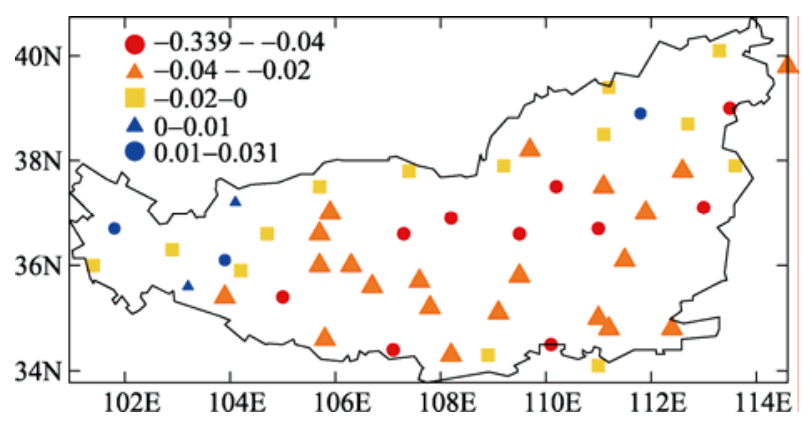

Fig. 2 The spatial distribution of the annual humidity index

\subsection{Anomaly distribution for dry and wet conditions}

The analyze on the temporal distribution of the annual average humidity index for 50 stations in the research areas by using principal components (PC) and rotated principal components (RPC) revealed that the loading vectors (LV) and rotated loading vectors (RLV) were able to better reflect the anomaly characteristics of spatial distributions of the annual average index. Table 1 shows the percentage contribution to whole variance of PCs and RPCs. It can be seen that the convergence of PC and RPC increased with the expansion of the time scale and the increase of detection stations, which showed large temporal and spatial differences of terrestrial surface dry and wet conditions in each 
area due to the vastness and the large terrain differences in the research areas. In addition, the contribution of each component after rotation to the variance is better distributed than those before rotation, and meanwhile the measurement and sequence of some variance components have changed. Because the physical significance for each rotated component lays emphasis on representing the distributional characteristics of spatial correlation, the relevant variance contribution only focuses on a small area to reduce variance contributions in other areas to the greatest extent, whereas principal component analysis emphasizes centering the variance contribution in the overall computer capacity on the first few PCs.

Another characteristic of the percentage contribution of the PCs before rotation is that the first 2 modes are obviously bigger than normal and their percentage contribution to the whole variance reaches $58.03 \%$. Therefore, the first 2 modes are two most primary spatially anomal modes for terrestrial surface dry and wet conditions on China's Loess Plateau. It can be seen from the spatial distribution of the first EOF mode (Fig. 3) that the positive values for each research area indicate that the terrestrial surface dry and wet conditions on the Loess Plateau displayed a consistent phase change. Such changing characteristics show that the Loess Plateau is a transitional zone from monsoon regions in eastern China to arid regions in western
China and has consistent phases of terrestrial surface dry and wet conditions under the control of the same large-scale weather system (Zhang et al., 2003). North Shaanxi, West Shanxi, East Gansu and South Ningxia have the maximal loading values, which show that these regions are the most likely to experience anomalies in terrestrial surface dry and wet conditions. In the interior region of the Loess Plateau, these are core areas of the Loess Plateau and experience high rates of change in climatic factors, resulting in high rates of change of dry and wet conditions and anomalies. southeast Shanxi and Central Shaanxi Plains have lower loading values, which indicate lower rates of anomalies in terrestrial surface dry and wet conditions.

The spatial distribution of the second EOF mode (Fig. 3) shows that the LV values for the south Loess Plateau were positive, with the Central Shaanxi Plains having the maximum value; the LV values for the north Loess Plateau were negative, with the northwestern part and northeastern parts of the Loess Plateau having the maximum value. The phase distribution for the second LV appeared in reverse order in the north and south of the Loess Plateau with appropriately equal absolute values. It means that the mode has reflected the anti-phase distributional characteristics for terrestrial surface dry and wet conditions in the north and south of Loess Plateau. In

Table 1 The percentage contribution to whole variance of the first ten PCs and RPCs

\begin{tabular}{ccccccccccc}
\hline Parameter (\%) & 1 & 2 & 3 & 4 & 5 & 6 & 7 & 8 & 9 & $\begin{array}{c}\text { Accumulated percentage } \\
\text { of contribution (\%) }\end{array}$ \\
\hline Percentage of contribution of PC & 47.89 & 10.14 & 7.75 & 4.62 & 4.30 & 3.08 & 2.69 & 2.18 & 2.16 & 1.61 \\
Percentage of contribution of RPC & 19.71 & 8.60 & 18.75 & 7.48 & 3.94 & 5.10 & 9.26 & 3.49 & 7.61 & 2.49 \\
\hline
\end{tabular}
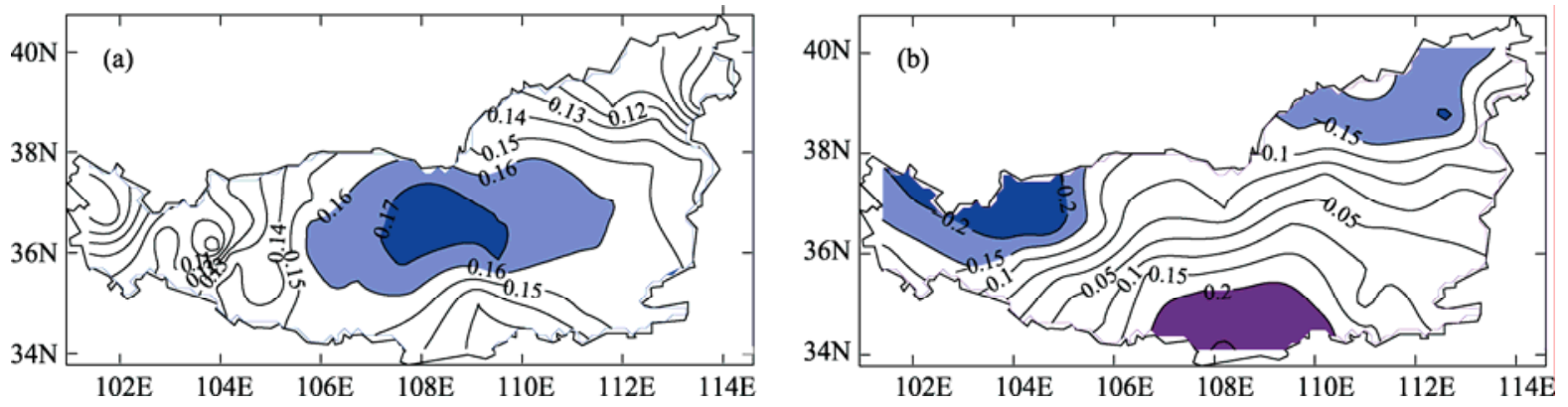

Fig. 3 Spatial distribution of the first two main modes of EOF 
fact, because north Loess Plateau is subject to cold air from the north and south Loess Plateau is subject to subtropical highs, the phenomenon of inconsistent phase change for the second mode LV of dry and wet conditions occurs in the north and south Loess Plateau.

In order to further analyze the sub-regional change of terrestrial surface dry and wet conditions in the Loess Plateau, the first 10 PCs and their corresponding LVs are rotated to obtain RLVs.

Another important characteristic for the RPC percentage to whole variance is that the first 3 modes are obviously greater than normal, the percentage contribution of their values to whole variance reaching $47.05 \%$. It follows that the first 3 modes are three most primary spatially anomal modes for terrestrial surface dry and wet conditions in the Loess Plateau (Fig. 4). All shaded areas in Fig. 4 are where the RLV absolute value is larger than 0.5 .

As the first REOF mode (Fig. 4a) indicates, the maximum values of RLV are in the central Shaanxi Plains and East Gansu with the central value of 0.88 and the representative station of Baoji in Shaanxi $\left(107.1^{\circ} \mathrm{N}, 34.4^{\circ} \mathrm{E}\right)$. These areas lie in south Loess Plateau and are mainly influenced by the East Asian monsoon.

As the second REOF mode (Fig. 4b) indicates, the maximum values of RLV lie in the middle part of Gansu with the central value of -0.84 and the representative station of Huajialing in Gansu $\left(105.0^{\circ} \mathrm{N}\right.$, $\left.35.4^{\circ} \mathrm{E}\right)$. These areas are in the west Loess Plateau and are jointly influenced by westerlies, the Tibetan Plateau monsoon and the East Asian monsoon.

As the third REOF mode (Fig. 4c) indicates, the maximum values of RLV are in the middle part of Shanxi with the central value of 0.81 and the representative station of Yushe in Shanxi $\left(113.0^{\circ} \mathrm{N}, 37.1^{\circ} \mathrm{E}\right)$. These areas are mainly influenced by westerlies and the East Asian monsoon.

Based on the spatial distribution of LV modes of the REOF, the spatial distribution of the terrestrial surface dry and wet conditions on the Loess Plateau can be divided into three regions, namely the south Loess Plateau, the northwest Loess Plateau and the east Loess Plateau.
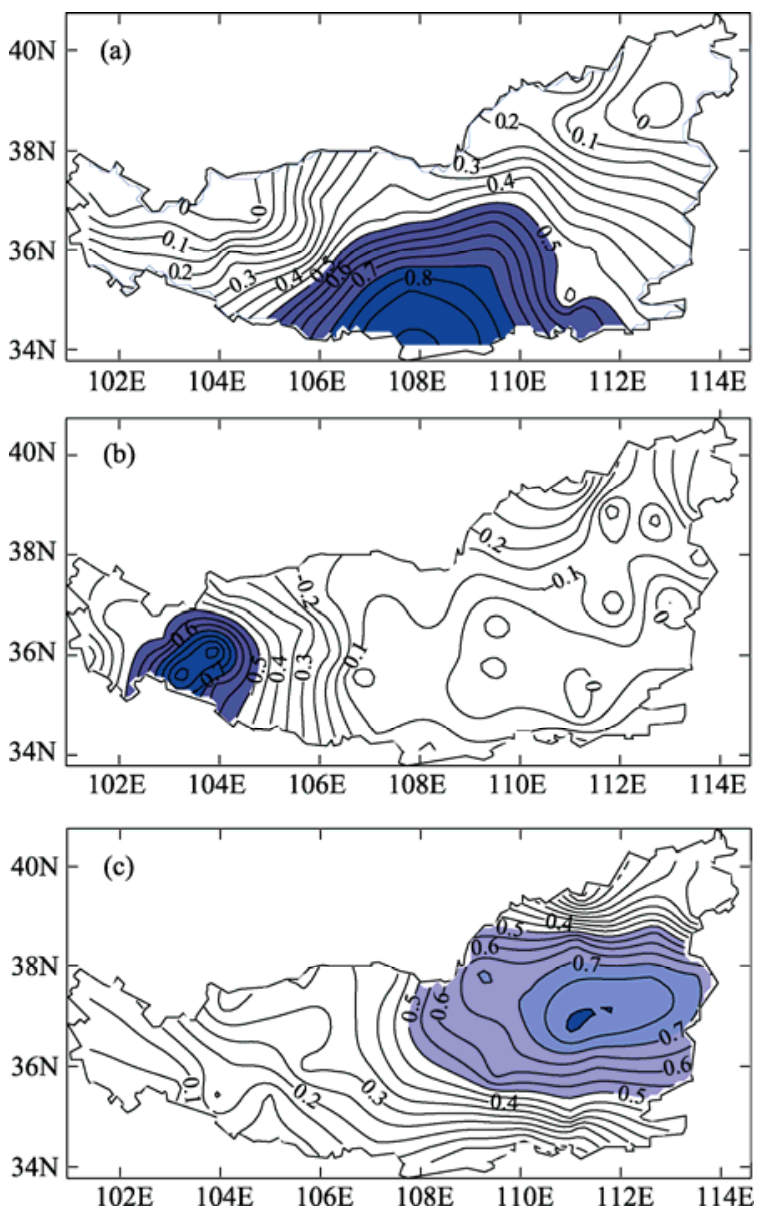

Fig. 4 Spatial distribution of the first three main modes of REOF

\subsection{Sub-regional temporal evolution of dry and wet conditions}

\subsubsection{Tendency analysis}

As each representative station corresponding to a spatial distribution of LV modes of the REOF can represent the changing characteristics of terrestrial surface dry and wet conditions in this area, the temporal distribution of humidity index for each station can be used to analyze the long-term trends of terrestrial surface dry and wet conditions in each sub-region.

Table 2 shows the trend coefficient and tendency rate of annual terrestrial surface humidity index for representative stations in each subregion for the past 48 years. It can be seen that annual humidity index decreased quickly in Yushe in the east Loess Plateau with the tendency rate of $-0.071 / 10 \mathrm{a}$, and passed the trend coefficient of 0.33 and 0.05 reliability testing. The humidity index decreased less quickly in Baoji of south Loess Plateau with the tendency rate of 
$-0.058 / 10$ a, and passed the trend coefficient of 0.36 and 0.01 reliability testing. Huajialing of west Loess Plateau shows the slowest decreasing speed of annual humidity index with the tendency rate of $-0.046 / 10 \mathrm{a}$, and passed the trend coefficient of 0.39 and 0.01 reliability testing.

Table 2 Trend coefficients and tendency rates of representative stations

\begin{tabular}{cccc}
\hline & \multicolumn{3}{c}{ Representative station } \\
\cline { 2 - 4 } & Baoji & Huajialing & Yushe \\
\hline Trend coefficient & 0.36 & 0.39 & 0.33 \\
Tendency rate/10 a & -0.058 & -0.046 & -0.071 \\
\hline
\end{tabular}

According to the trend analysis, the annual terrestrial surface humidity index on the Loess Plateau displayed a decreasing trend over the past 48 years. Yushe of east Loess Plateau comes out first, followed in proper order by Baoji of south Loess Plateau and Huajialing of west Loess Plateau.

\subsubsection{Abrupt change detection}

In order to detect abrupt changes of the annual terrestrial surface humidity index of each subarea on the Loess Plateau over the past 48 years, the study carried out abrupt change testing on the annual humidity index temporal distribution for the representative stations using the M-K method. Figure 5 displays $\mathrm{M}-\mathrm{K}$ test curve of the representative stations. In Fig. 5, UF refers to ordinal statistics curve (solid line) of the humidity index and UB refers to converse statistics curve (dashed line) of the humidity index. When $\alpha=0.05$, the critical line is $\mathrm{U}_{\alpha}=1.96$. According to Fig. $5 \mathrm{a}$, it can be seen that the annual terrestrial surface humidity index of Baoji began to decrease after 1976 and UF surpassed $U_{\alpha}$ in 1977, which indicated a dramatic decrease. In 1977, UF and UB intersected with the point of intersection falling between critical lines. This indicates that the abrupt change occurred in 1977, that is to say 1977 was the abrupt changing point for significant aridification. The annual terrestrial surface humidity index of Huajialing began to decrease after 1967 (Fig. 5b) and the decrease has accelerated since 1995 with the UF line coming up to the reliability testing. The abrupt change occurred in 1971. The annual terrestrial surface humidity index of Yushe began to decrease after 1978 (Fig. 5c) and the
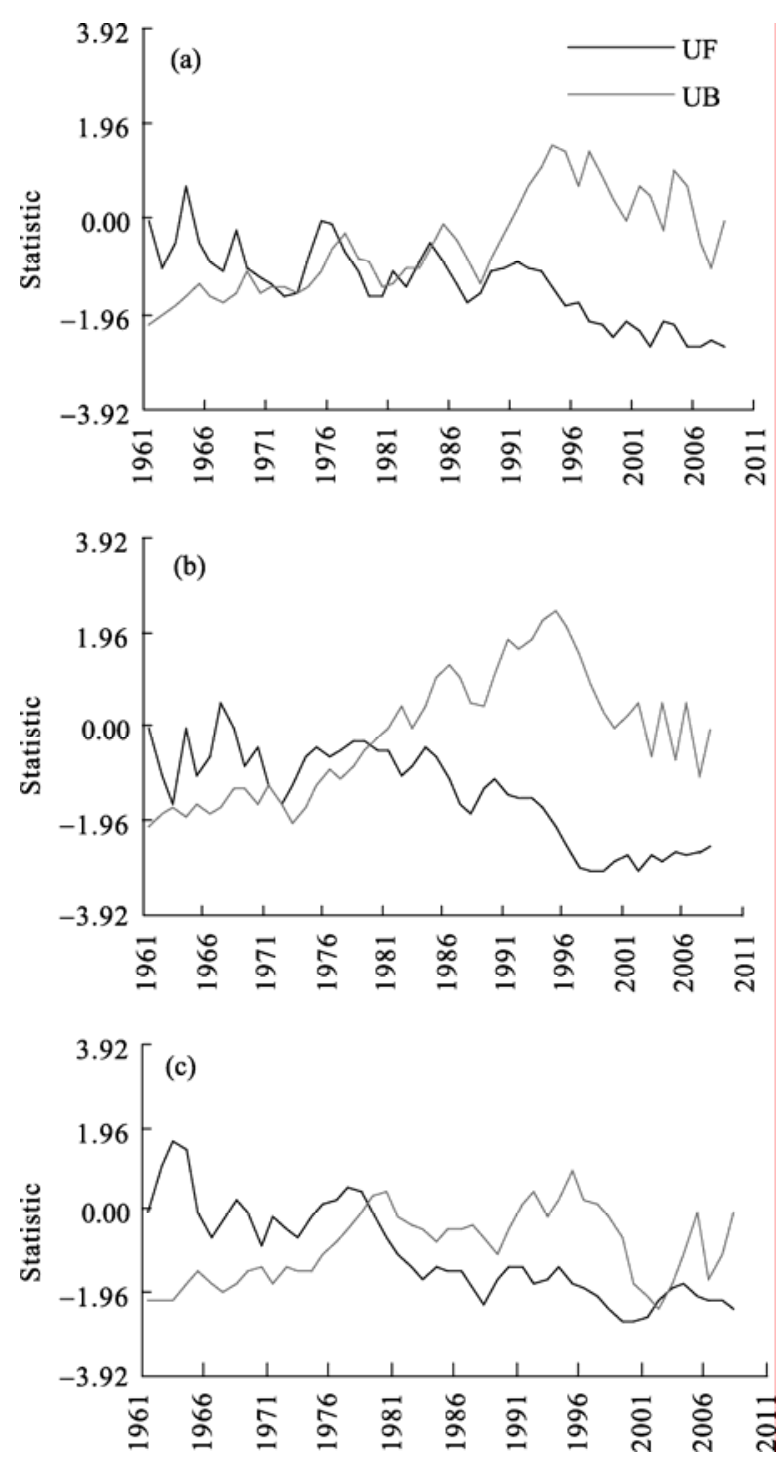

Fig. 5 M-K check curve of representative stations

decrease has accelerated since 1998 with the UF line coming up to the reliability testing. The abrupt change occurred in 1979.

It can be seen that the annual terrestrial surface humidity indices of the three representative stations on the Loess Plateau displayed a decreasing trend over the past 48 years, with abrupt changes for Baoji, Huajialing and Yushe occurring in 1977, 1967 and 1979, respectively.

\subsubsection{Period analysis}

This study, using wavelet analysis and based on the temporal distribution of annual terrestrial surface humidity indexes for each representative station, 
revealed the periodic features of terrestrial surface dry and wet conditions on China's Loess Plateau over the past 48 years. From the isoline chart of the boundaryavailable Morlet wavelet energy spectrum, the annual terrestrial surface humidity index of Baoji was found to experience a remarkable 7-8a fluctuating period over the past 48 years, which developed most intensely in the 1970s. In addition, a 3-4a fluctuating period also existed at the same time, which developed more intensely during approximately 1965-1975 and 2002-2003 (Fig. 6a); the annual terrestrial surface humidity index of Huajialing presented a 3-4a fluctuating period in the past 48 years, which developed most intensely in the 1960s (Fig. 6b); the annual terrestrial surface humidity index of Yushe showed a 3-4a fluctuating period over the past 48 years, which developed most intensely in the 1960s and with greater intensely during 1987-1995 (Fig. 6c).
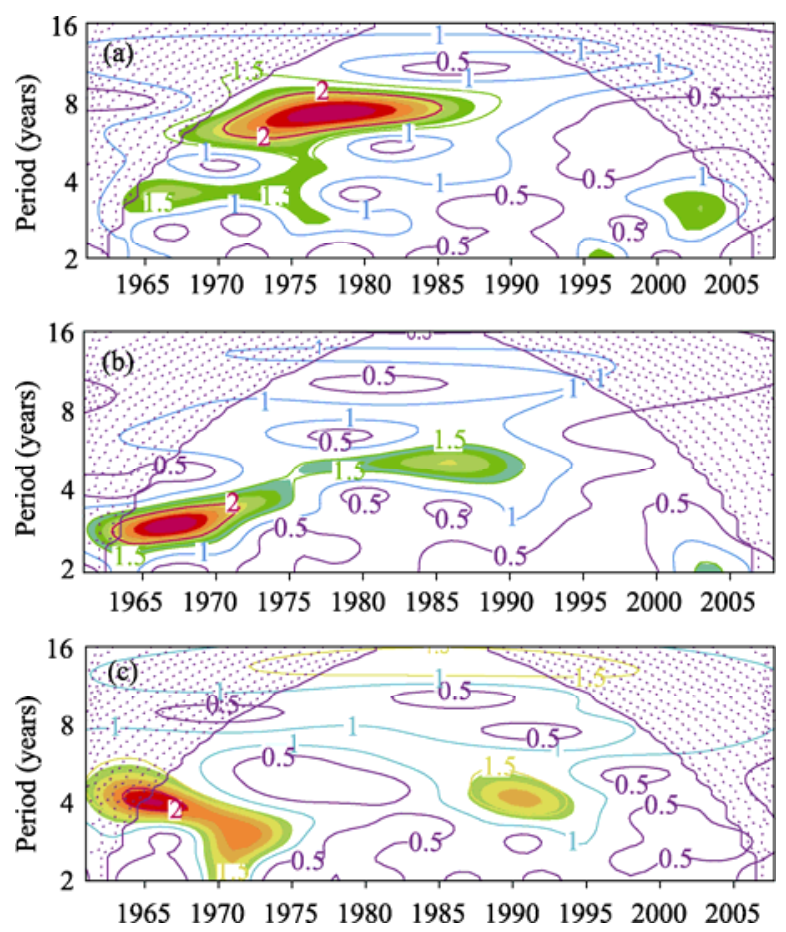

Fig. 6 Isoline chart of Morlet wavelet energy spectrum for representative stations

\section{Possible causes of changes in terr- estrial surface dry and wet conditions}

According to the researches on annual terrestrial surface humidity index of northwestern areas, it was found that the humidity index and precipitation had obviously positive correlations with the relative humidity and significantly negative correlations with the sunshine hours, potential evapotranspiration and wind speed. By studying the dry and wet conditions in Xinjiang, Jiang et al. (2009) found that the climate of Xinjiang was normal on the average during 19612003 after which a major changing feature of humidification began. This was mainly caused by increase of precipitation. Yao et al. (2011a) found that the major factors influencing the annual terrestrial surface humidity index of Sanjiangyuan area are precipitation, relative humidity and mean maximum temperature. In the recent 50 years, there have been remarkable changes in the precipitation and potential evapotranspiration in the northwestern areas, the change rate of which is strongly related to humidification and aridification. As temperature is the major climatic factor influencing the exchange of substance and energy, increases in temperature will result in increases of maximum potential evapotranspiration (Yao et al., 2011b), and reduction of precipitation, which in turn causes reduction of the terrestrial surface humidity index and warming-drying climatic tendency. From this, it can be seen that major climatic factors for change of terrestrial surface dry and wet conditions on the Loess Plateau are temperature, precipitation and maximum potential evapotranspiration.

This paper analyzed the changing feature of terrestrial surface dry and wet conditions on the Loess Plateau from the perspective of climatic change. However, the combination of terrain landform, climatic factors, distribution features of greenhouse gas and human activities will be helpful for a more definite understanding of the changing and anomaly distriution of terrestrial surface dry and wet conditions on the Loess Plateau.

\section{Conclusions}

(1) The annual average terrestrial surface humidity index showed a decreasing trend along the route from the southeast to northwest in the study area. The northwestern part of the Loess Plateau is mainly a semi-arid area and its southeastern part is mainly a semi-humid area. The spatial distribution of the annual 
average humidity index in the study area is directly proportional in terms of phase change to the spatial distribution of its annual precipitation and annual mean temperature. With the exception of some regions in the western areas, the annual humidity index of the Loess Plateau showed a decreasing trend, demonstrated by significance tests at a majority of stations. It showed that aridification tendency appeared sharply in the interior region, and less sharply in the middle part of the region. The border region had the weakest tendency of aridification (some regions in the western part had the tendency of humidification). It is clear that aridification has diffused in all directions from the interior region.

(2) Consistency of the spatial distribution for the first EOF mode in the study area is the primary spatial mode; whereas it is important that the distribution of second mode LV on the north and south Loess Plateau appeared in reverse order. According to the spatial distribution of LV mode of the REOF, the maximum potential evapotranspiration space on Loess Plateau can be divided into 3 sub-regions: south Loess Plateau which is mainly influenced by East Asian monsoon; west Loess Plateau which is jointly influenced by westerlies, Tibetan Plateau monsoon and East Asian monsoon; and east Loess Plateau which is mainly influenced by westerlies and East Asian monsoon.

(3) The surface annual average humidity index of the three key spatial subregions in the research areas displayed a significantly descending trend over the past 48 years. The southern, western and eastern regions of the Loess Plateau exhibited remarkable abrupt changes from wet to dry in the year 1967, 1977 and 1979 , respectively.

(4) The surface annual humidity index of the research areas over the past 48 years showed an obvious fluctuating period of $3-4 \mathrm{a}$; while in the southern region of the plateau an obvious fluctuating period of 7-8 a existed at the same time.

This research has demonstrated a synthesis of several methodologies, among these the Penman-Monteith model to calculate the humidity index, Morlet wavelet energy spectrum analysis to diagnose abrupt change points, the Mann-Kendall (M-K) trend test for trend analysis of climatic data, and the experiential orthogonal function and the rotated experiential orthogonal function analysis to characterize spatial anomaly distributions. These methods will be useful for future research on changes in terrestrial surface dry and wet conditions and more generally on climate change influences on water dynamics in the soil-vegetation-atmosphere continuum.

\section{Acknowledgements}

This work was financially supported by the National Basic Research Program of China (2012CB955903, 2012CB955304), the Special Fund for Public Welfare Industry (GYHY201106029, GYHY200806021), the National Natural Science Foundation of China (40830957), the China Meteorological Administration Special Program for Climatic Change (280200S011C00), and the Drought Meteorology Science Research Program (IAM201111).

\section{References}

Allen R G, Pereira L S, Raes D, et al. 1998. Crop evapotranspiration: guidelines for computing crop water requirements. FAO Irrigation and Drainage Paper 56. Rome: FAO.

Chattopadhyay N, Hulme M. 1997. Evaporation and potential evapotranspiration in India under conditions of recent and future climate change. Agricultural and Forest Meteorology, 87: 55-73.

Chen S B, Liu Y F, Axel Thomas. 2006. Climatic change on the Tibetan Plateau: potential evapotranspiration trends from 1961-2000. Climatic Change, 76: 291-319.

Ci L J, Yang X H, Chen Z X. 2002. The potential impacts of climate change scenarios on desertification in China. Earth Science Frontiers, 9(2): 287-294.

Deng G Y. 1979. A climatic calculative method of evaporation from open water. Acta Meteorologica Sinica, 37(3): 87-96.

Ding Y G, Shi N. 1992. Research on convergence of the eigenvalues for the EOFs expansion of meteorological field among different schemes. Chinese Journal of Atmospheric Sciences, 16(4): 436-443.

Du J, Li C, La B, et al. 2009. Climatic changes of terrestrial surface humid index and its impact factors over Tibet in recent 35 years. Acta Meteorologica Sinica, 67(1): 158-164.

Guo R, Li F M, He W Y, et al. 2011. Spatial and temporal variability of annual precipitation during 1958-2007 in Loess Plateau, China. In: IFIP. Advances in Information and Communication Technology, 345: 551-560.

IPCC. 2007. Climate Change 2007: Impacts, Adaptation and Vulnerability. In: Parry M L, Canziani O F, Palutikof J P, et al. Contribution of Working Group II to the Fourth Assessment Report of the Intergovernmental Panel on Climate Change. Cam $\neg$ bridge and Newyork: Cambridge University Press.

IPCC. 2012. Summary for Policymakers. In: FieldC B, Barros V, Stocker $\mathrm{T} F$, et al. Managing the Risks of Extreme Events and Disasters to 
Advance Climate Change Adaptation. A Special Report of Working Groups I and II of the Intergovernmental Panel on Climate Change. Cambridge and New York: Cambridge University Press, 1-19.

Jesen M E, Burman R D, Allen R G. 1990. Evapotranspiration and irrigation water requirements. In: Jensen M E, Burman R D, Allen RG. ASCE Manuals and Reports on Engineering Practice No. 70. New York: American Society of Civil Engineer, 80-112.

Jiang D B, Su M F, Wei R Q, et al. 2009. Variation and projection of drought and wet conditions in Xinjiang. Chinese Journal of Atmospheric Sciences, 33(1): 90-98.

Kendall M G. 1975. Rank Correlation Methods. London: Griffin.

Li H X, Liu G H, Fu B J. 2012. Estimation of regional evapotranspiration in alpine area and its response to land use change: a case study in Three-River Headwaters region of Qinghai-Tibet Plateau, China. Chinese Geographical Science, 22(4): 437-449.

Liu Q, Yang Z F, Cui B S. 2008. Spatial and temporal variability of annual precipitation during 1961-2006 in Yellow River Basin, China. Journal of Hydrology, 361: 330-338.

Liu W Q, Wang F T. 2002. Analysis on vulnerability of agro-production to climate change in the Loess Plateau. Journal of Nanjing Institute of Meteorology, 25(5): 620-624.

Lu A G. 2009. Spatial and temporal precipitation variation on the Loess Plateau in the past half century. Ecology and Environmental Sciences, 18(3): 957-959.

Ma Z G, Fu C B. 2001. Trend of surface humid index in the arid area of northern China. Acta Meteorologica Sinica, 59(6): 737-746.

Ma Z G, Fu C B. 2005. Decadal variations of arid and semi-arid boundary in China. Chinese Journal of Geophysics, 48(3): 519-525.

Ma Z G. 2005. Dry/wet variation and its relationship with regional warming in arid-regions of northern China. Chinese Journal of Geophysics, 48(5): 1011-1018.

Mann H B. 1945. Nonparametric tests against trend. Econometrica, 13: 245-259.

Mitchell J M, Dzerdzeevskii B, Flohn H, et al. 1966. Climate change. In: WMO Technical Note No. 79. Geneva: World Meteorological Organization.

Shen S H, Zhang F M, Sheng Q. 2009. Spatio-temporal changes of wetness index in China from 1975 to 2004. Transactions of the CSAE, 25(1): 11-15.

Thomas A. 2000. Spatial and temporal characteristics of potential evapotranspiration trends over China. International Journal of Climatology, 20: 381-396.

Walter I A, Allen R G, Elliott R, et al. 2000. ASCE's standardized reference evapotranspiration equation. In: Evans R G, Benham B L, Trooien T P. Proceedings of the National Irrigation Symposium, ASAE. Phoenix: ASCE, 1-6.

Wang P X, Yang J H. 2007. Extreme high temperature events and response to regional warming in recent 45 years in northwest China. Journal of Desert Research, 27(4): 649-654.
Wang Y Q, Fan J, Shao M A, et al. 2008a. Analysis of effects of climate change on reference evapotranspiration on the Loess Plateau in recent 50 years. Transactions of the CSAE, 24(9): 6-10.

Wang W, Chen X, Shi P, et al. 2008b. Detecting changes in extreme precipitation and extreme streamflow in the Dongjiang River Basin in southern China. Hydrology and Earth System Science, 12: 207-221.

Wang Y R, Yin X Z, Yuan Z P. 2004. Main characteristics of climate system in Loess Plateau in China. Journal of Catastrophology, 19(z1): 40-47.

Wei F Y. 2007. Statistic Diagnose and Foreshadow Technology in Present Climate. Beijing: Meteorological Press, 115-131.

Wu H B, Wu L. 2005. Methods for Diagnosing and Forecasting Climate Variability. Beijing: Meteorological Press, 208-244.

Wu S H, Yin Y H, Zheng D, et al. 2005. Study of dry and wet state in recent 30 years in China. Science in China: Series D, 35(3): 276-283.

Xie X Q, Wang L. 2007. Changes of potential evaporation in northern China over the past 50 years. Journal of Natural Resources, 22(5): 684-690.

Yao Y B, Wang Y R, Li Y H, et al. 2005. Climate warming and drying and its environmental effects in the Loess Plateau. Resources Science, 27(5): 146-152.

Yao Y B, Yang J H, Yue P, et al. 2011a. Climatic change of terrestrial surface humid index and its impact factors over the source region of three rivers in recent 50 years. Ecology and Environmental Sciences, 20(11): 1585-1593.

Yao Y B, Wang R Y, Yang J H, et al. 2011b. Change of terrestrial surface potential evapotranspiration in Loess Plateau. Ecology and Environmental Sciences, 20(8-9): 1189-1195.

Zhang J Y, Dong W J, Fu C B, et al. 2003. The influence of vegetation cover on summer precipitation in China: a statistical analysis of NDVI and climate data. Advances in Atmospheric Sciences, 20(6): 1002-1006.

Zhang Q, Liu C L, Xu C Y, et al. 2006. Observed trends of annual maximum water level and streamflow during past 130 years in the Yangtze River basin, China. Journal of hydrology, 324: 255-265.

Zhang Q, Deng Z Y, Zhao Y D, et al. 2008. The impacts of global climatic change on the agriculture in northwest China. Acta Ecologica Sinica, 28(3): 1210-1218.

Zhang Q, Sun Z X, Wang S. 2011. Analysis of variation regularity of land-surface physical quantities over Dingxi region of the Loess Plateau. Chinese Journal of Geophysics, 54(7): 1727-1731.

Zhao Y X, Wang F T, Liu W Q. 2003. Climatic ecological environment, climate change and agricultural productivity in Loess P1ateau. Agricultural Research in the Arid Areas, 21(4): 142-147.

Zhou L S. 2000. China's Agro-geography. Beijing: Science Press, 347-364.

Zuo D K, Wang Y X, Chen J S. 1993. Spatial Distribution Characters of Solar Radiation in China. In: Zuo D K. Geographical Research Paper. Beijing: Science Press, 168-185. 